\title{
Dyspnea in COPD: New Mechanistic Insights and Management Implications
}

Denis E. O'Donnell - Kathryn M. Milne - Matthew D. James •

Juan Pablo de Torres · J. Alberto Neder

Received: September 10, 2019 / Published online: October 30, 2019

(C) The Author(s) 2019

\section{ABSTRACT}

Dyspnea is the most common symptom experienced by patients with chronic obstructive pulmonary disease (COPD). To avoid exertional dyspnea, many patients adopt a sedentary lifestyle which predictably leads to extensive skeletal muscle deconditioning, social isolation, and its negative psychological sequalae. This "dyspnea spiral" is well documented and it is no surprise that alleviation of this distressing symptom has become a key objective highlighted across COPD guidelines. In reality, this important goal is often difficult to achieve, and successful symptom management awaits a

Enhanced Digital Features To view enhanced digital features for this article go to https://doi.org/10.6084/ m9.figshare.9970322.

D. E. O'Donnell $(\bowtie) \cdot$ K. M. Milne · M. D. James Respiratory Investigation Unit, Division of Respirology, Department of Medicine, Kingston Health Sciences Centre and Queen's University, Kingston, ON, Canada

e-mail: odonnell@queensu.ca

K. M. Milne

Clinician Investigator Program, Department of Medicine, University of British Columbia,

Vancouver, BC, Canada

J. P. de Torres · J. A. Neder

Division of Respirology, Department of Medicine, Kingston Health Sciences Centre and Queen's

University, Kingston, ON, Canada clearer understanding of the underlying mechanisms of dyspnea and how these can be therapeutically manipulated for the patients' benefit. Current theoretical constructs of the origins of activity-related dyspnea generally endorse the classical demand-capacity imbalance theory. Thus, it is believed that disruption of the normally harmonious relationship between inspiratory neural drive (IND) to breathe and the simultaneous dynamic response of the respiratory system fundamentally shapes the expression of respiratory discomfort in COPD. Sadly, the symptom of dyspnea cannot be eliminated in patients with advanced COPD with relatively fixed pathophysiological impairment. However, there is evidence that effective symptom palliation is possible for many. Interventions that reduce IND, without compromising alveolar ventilation $\left(V_{\mathrm{A}}\right)$, or that improve respiratory mechanics and muscle function, or that address the affective dimension, achieve measurable benefits. A common final pathway of dyspnea relief and improved exercise tolerance across the range of therapeutic interventions (bronchodilators, exercise training, ambulatory oxygen, inspiratory muscle training, and opiate medications) is reduced neuromechanical dissociation of the respiratory system. These interventions, singly and in combination, partially restore more harmonious matching of excessive IND to ventilatory output achieved. In this review we propose, on the basis of a 
thorough review of the recent literature, that effective dyspnea amelioration requires combined interventions and a structured multidisciplinary approach, carefully tailored to meet the specific needs of the individual.

Keywords: COPD; Dyspnea; Respiratory physiology

\section{Key Summary Points}

Dyspnea is the most common symptom in chronic obstructive pulmonary disease (COPD), resulting in significant morbidity and alleviating dyspnea is a key objective of COPD management

Dyspnea is believed to result from disruption of the normal relationship between inspiratory neural drive (IND) to breathe and the dynamic response of the respiratory system

Therapeutic interventions including bronchodilators, exercise training, ambulatory oxygen, inspiratory muscle training, and opiates can reduce dyspnea by reducing neuromechanical dissociation of the respiratory system

Dyspnea management is challenging, and effective management requires combined interventions and a multidisciplinary approach tailored to the individual patient

\section{INTRODUCTION}

Dyspnea is defined as "a subjective experience of breathing discomfort that consists of qualitatively distinct sensations that vary in intensity" and is the most common symptom in chronic obstructive pulmonary disease (COPD) [1]. Chronic dyspnea decreases engagement in physical activity and is associated with reduced health-related quality of life and increased mortality [2, 3]. The mechanisms of dyspnea are complex and incompletely understood, and effective management of this distressing symptom is difficult. However, a personalized, patient-focused approach based on an understanding of the underlying mechanisms can yield meaningful benefits for many.

The overarching objectives of this review are (1) to consider current constructs of the neurophysiological mechanisms of activity-related breathlessness in patients with COPD, (2) to examine mechanisms of benefit of a variety of therapeutic interventions currently at our disposal, and (3) to review the evidence of the clinical efficacy of these treatments.

For the purpose of this review, the terms dyspnea, breathing discomfort, and breathlessness are used interchangeably. As a result of space constraints, the effects of endoscopic or surgical lung volume reduction and non-invasive mechanical ventilation are not discussed. This article is based on previously conducted studies and does not contain any studies with human participants or animals performed by any of the authors.

\section{CURRENT CONSTRUCTS OF DYSPNEA CAUSATION}

Quoting the renowned Canadian physiologist Norman Jones [4]: "breathlessness can be seen to result from the imbalance between the demand for breathing and the ability to achieve the demand." Accordingly, breathlessness is invariable when there is a mismatch between increased inspiratory neural drive (IND) and an inadequate mechanical response of the respiratory system. This general "imbalance" concept is intuitively appealing and widely supported. This phenomenon has variously been termed demand-capacity imbalance, efferent-afferent dissociation, neuromuscular or neuromechanical dissociation.

Normally in health, unpleasant respiratory sensation is avoided as spontaneous breathing is unimpeded and neuromechanical harmony of the respiratory system is intact [5]. However, unpleasant respiratory sensation can be provoked in healthy volunteers during 
experimental chemical and respiratory mechanical loading [6-10]. For example, when spontaneous tidal volume $\left(V_{\mathrm{T}}\right)$ expansion is constrained in the face of increased or persistent chemostimulation, unpleasant respiratory sensations (e.g., "sense of air hunger") are consistently perceived [11]. The same is true of young healthy subjects during exercise: combined chemical (added 0.6 L dead space, equivalent to $\mathrm{CO}_{2}$ rebreathing) and external mechanical loading (chest wall strapping to constrain $V_{\mathrm{T}}$ expansion) amplified intensity of breathing discomfort and exercise intolerance to a much greater extent than either intervention in isolation [12].

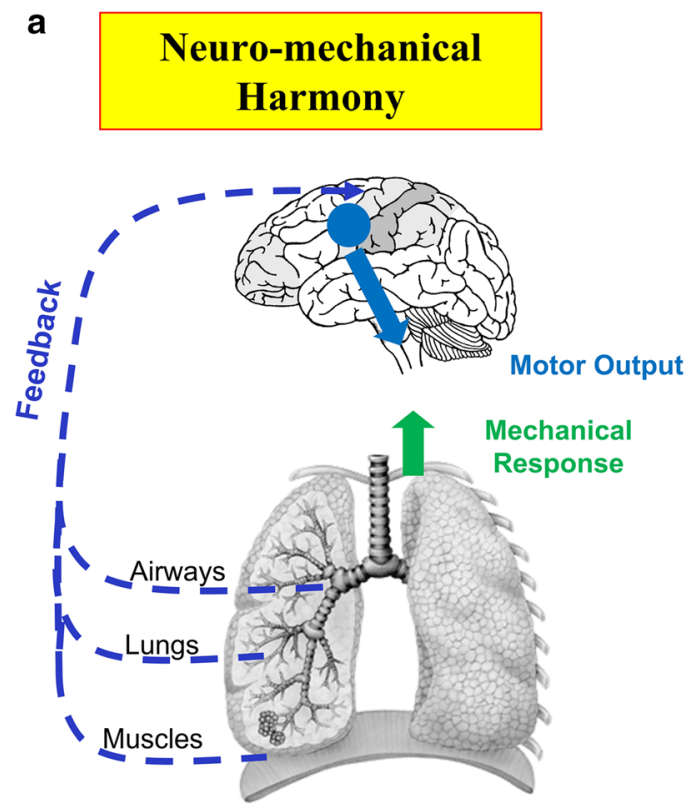

Fig. 1 a Neuromechanical harmony and $\mathbf{b}$ dissociation in a patient with COPD during exertion. a Synchronous activation of the respiratory and locomotor muscles with progressive motor command output increases to maintain ventilation with activity initiation. b Arterial oxygen desaturation, increased $\left[\mathrm{H}^{+}\right]$, and increased $\mathrm{VCO}_{2}$ with corresponding chemostimulation of medullary centers and increased IND as exercise continues. Resting and dynamic hyperinflation and resulting mechanical constraints lead to neuromechanical dissociation and distressing unsatisfied

\section{NEUROPHYSIOLOGY OF DYSPNEA}

Briefly, information on the amplitude of motor command output from respiratory control centers in the medulla and cerebral cortex is relayed to the somatosensory cortex via central corollary discharge or efferent copy (Fig. 1) [13-15]. Direct chemostimulation of medullary-pontine centers is immediately associated with perceived severe breathing difficulty in healthy volunteers, even in the absence of any respiratory muscle activity [16]. It is believed that increased motor command output from cortical motor centers, in response to experimentally increased inspiratory muscle impedance or weakness, is consciously perceived as increased perceived respiratory effort $[6,16]$. During

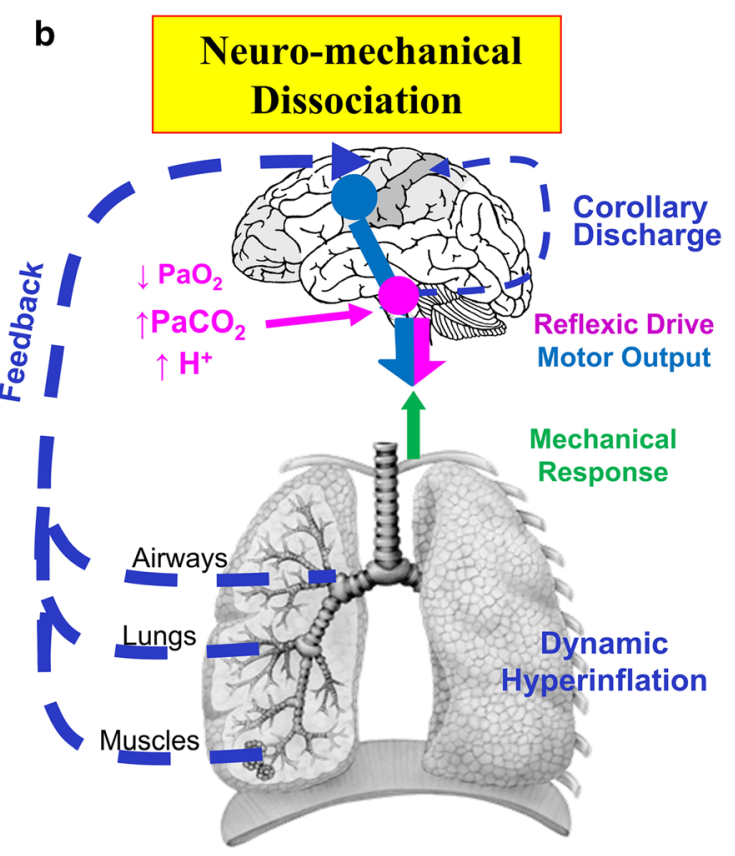

inspiration during exertion. COPD chronic obstructive pulmonary disease, $\left[\mathrm{H}^{+}\right]$hydrogen ion concentration, IND inspiratory neural drive, $\mathrm{PaCO}_{2}$ arterial partial pressure of carbon dioxide, $\mathrm{PaO}_{2}$ arterial partial pressure of oxygen, $\mathrm{VCO}_{2}$ carbon dioxide production. Reprinted from Clin Chest Med, 40(2): Denis E. O’Donnell, Matthew D. James, Kathryn M. Milne, J. Alberto Neder, The pathophysiology of dyspnea and exercise intolerance in chronic obstructive pulmonary disease, 343-366, Copyright (2019), with permission from Elsevier 
external mechanical loading, diverse afferent inputs from sensory receptors throughout the respiratory system are altered or disrupted and this information is conveyed to respiratory control centers and the somatosensory cortex. The collective sensory information from both central (brain) and peripheral (respiratory system) sources is centrally integrated and the net effect of efferent-afferent dissociation results in conscious perception of unpleasant respiratory sensations, e.g., unsatisfied inspiration [13-15].

Beyond a certain threshold, escalating breathing difficulty is experienced as an imminent threat to life or well-being, demanding immediate behavioral action [17]. Recent studies using functional magnetic resonance imaging (fMRI) of the brain have shown that when neuromechanical dissociation is experimentally induced by uncoupling of chemical stimulus and mechanical response, there is increased activation of limbic and paralimbic centers which, combined with sympathetic nervous system overactivation, results in anxiety, panic, and affective distress [18].

\section{EXERTIONAL DYSPNEA IN COPD}

The demand-capacity imbalance theory is supported by a number of studies which show strong statistical correlations between the rise in dyspnea intensity during exercise and simultaneous increase in a number of physiological ratios which ultimately reflect increased neuromechanical disruption (Table 1). Collectively, these data support the notion that dyspnea increases as a function of increasing IND (from bulbo-pontine and cortical respiratory control centers) in the face of an ever-decreasing capacity of the respiratory system to respond.

\section{Increased Inspiratory Neural Drive}

Diaphragm electromyography (EMGdi), measured using an esophageal catheter with multiple paired electrodes, generally gives a more accurate assessment of IND (EMGdi/EMGdi,$\max )$ than minute ventilation $\left(V_{\mathrm{E}}\right)$ or esophageal pressures which are strongly influenced by
Table 1 Physiologic ratios highly correlated with increasing dyspnea throughout exercise

\begin{tabular}{cl}
\hline Physiologic ratio & $\begin{array}{l}\text { Response during exercise and } \\
\text { significance }\end{array}$ \\
\hline$V_{\mathrm{E}} / \mathrm{MVC}$ & $\begin{array}{l}\text { Ventilation increasing to maximum } \\
{[103,104]}\end{array}$ \\
Pes/Pes,max & $\begin{array}{l}\text { Respiratory effort approaches } \\
{[6,105]}\end{array}$ \\
$V_{\mathrm{T}} / \mathrm{IC}$ & maximum volitional value \\
{$[88,89,106]$} & volume become critical \\
EMGdi/ & Tidal IND to the diaphragm \\
EMGdi,max & approaches maximum volitional \\
{$[19,20]$} & value \\
\hline
\end{tabular}

EMGdi diaphragmatic electromyography, EMGdi/ $E M G d$, max inspiratory neural drive, $I C$ inspiratory capacity, IND inspiratory neural drive, $M V C$ maximum ventilatory capacity, Pes esophageal pressure, Pes,max maximum esophageal pressure, $V_{T}$ tidal volume, $V_{E}$ minute ventilation

the prevailing dynamic mechanical constraints in COPD [19-23]. During cycle ergometry in patients with COPD (compared with age- and sex-matched healthy controls), EMGdi/ EMGdi,max is increased at rest and at any given level of oxygen consumption $\left(\mathrm{VO}_{2}\right)$ and $V_{\mathrm{E}}$ [24-26]. The slope of diaphragmatic activation versus work rate becomes steeper as pulmonary gas exchange and mechanical abnormalities worsen with COPD disease progression (Fig. 2) [24-26]. Remarkably, one recent study showed that the dyspnea-EMGdi/EMGdi,max slope is similar in subjects with COPD and those with interstitial lung disease (ILD) who have a similar resting inspiratory capacity (IC) reduction. This relationship held despite marked intergroup differences in lung compliance, breathing pattern, operating lung volumes, respiratory muscle recruitment pattern, and pulmonary gas exchange abnormalities [24]. Thus, dyspnea intensity/IND slopes were constant in these two diverse conditions despite vast differences in the source and type of afferent sensory inputs to the brain. 


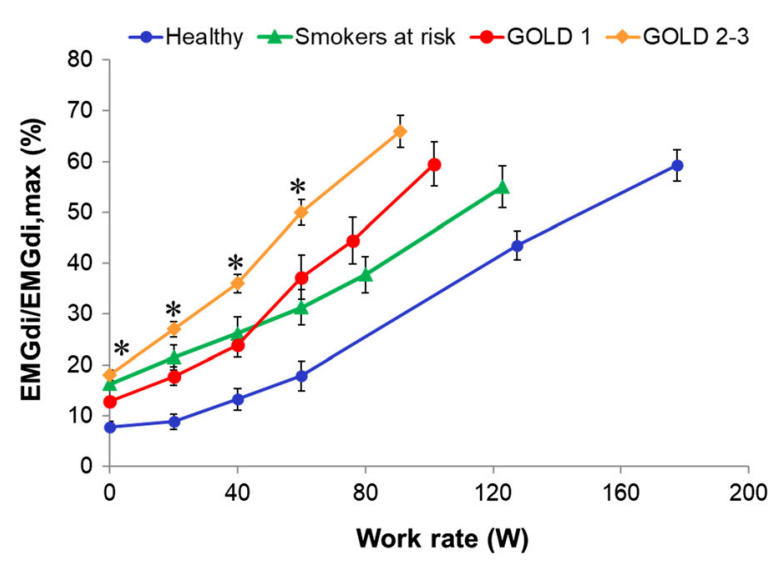

Fig. 2 Inspiratory neural drive during exercise represented by diaphragmatic activation as a percentage of maximal diaphragmatic activation (EMGdi/EMGdi,max) across healthy controls, smokers, and spectrum of COPD. Values are mean \pm SEM. ${ }^{*} p<0.05$ significantly different from healthy controls at a given work rate. COPD chronic obstructive pulmonary disease, EMGdi/EMGdi,max index of inspiratory neural drive to the crural diaphragm, GOLD Global Initiative for Chronic Obstructive Lung Disease, SEM standard error of the mean. Adapted from Guenette $\mathrm{JA}$, et al. Mechanisms of exercise intolerance in Global Initiative for Chronic Obstructive Lung Disease grade 1 COPD. Eur Respir J. 2014;44(5):1177-1187. Adapted from Elbehairy AF, et al. Mechanisms of exertional dyspnoea in symptomatic smokers without COPD. Eur Respir J. 2016;48(3):694-705. Reprinted with permission of the American Thoracic Society. Copyright (C) 2019 American Thoracic Society. Faisal A, Alghamdi BJ, Ciavaglia CE, Elbehairy AF, Webb KA, Ora J, Neder JA, O'Donnell DE. 2016. Common mechanisms of dyspnea in chronic interstitial and obstructive lung disorders. Am J Respir Crit Care Med. 193(3):299-309. The American Journal of Respiratory and Critical Care Medicine is an official journal of the American Thoracic Society

\section{Mechanisms of Increased Inspiratory Neural Drive in COPD}

\section{Pulmonary Gas Exchange Abnormalities and Acid-Base Imbalance}

The causes of increased IND during exercise in COPD include chemical and mechanical factors (Table 2) [19, 20, 24-26]. In both healthy controls and subjects with COPD, IND increases as
Table 2 Stimulus for increased inspiratory neural drive to the diaphragm

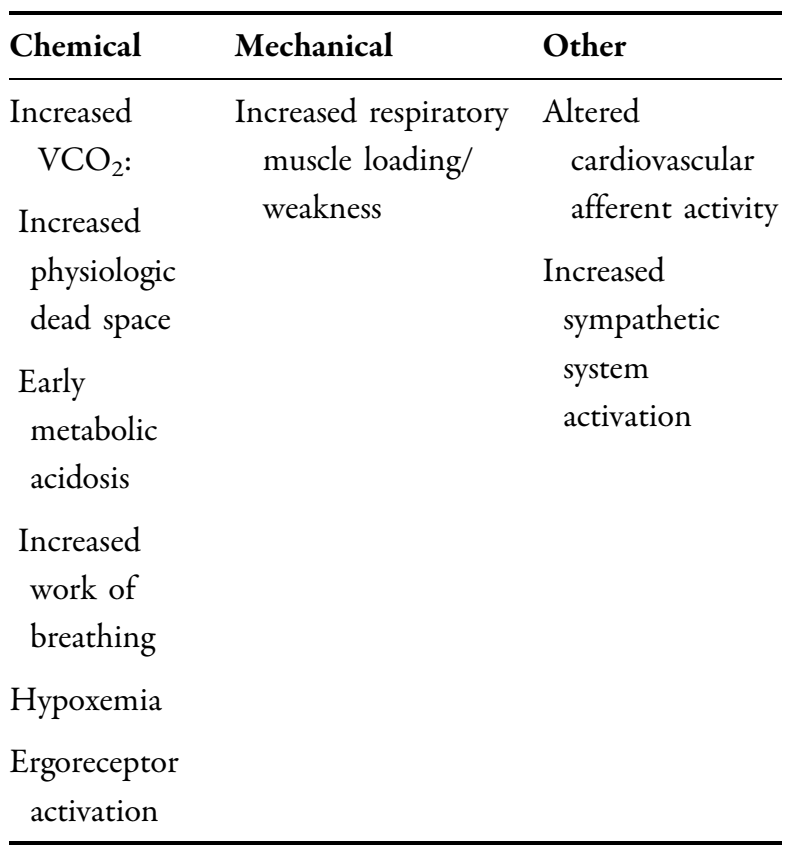

$\mathrm{VCO}_{2}$ carbon dioxide production

metabolic carbon dioxide output $\left(\mathrm{VCO}_{2}\right)$ increases during exercise. Thus, exercise hyperpnea is very closely linked to pulmonary $\mathrm{CO}_{2}$ gas exchange. In COPD, ventilation-perfusion mismatch in the lung leads to inefficient pulmonary gas exchange. Dysfunction of the lung microvasculature occurs to a variable extent across the entire severity spectrum of COPD [27-29]. In mild COPD during exercise, physiological dead space, the ventilatory equivalent for $\mathrm{CO}_{2}\left(V_{\mathrm{E}} / \mathrm{VCO}_{2}\right)$ - a measure of ventilatory efficiency-and alveolar ventilation $\left(V_{\mathrm{A}}\right)$ are all elevated, compared with healthy controls [27]. It is now clear that these high ventilatory requirements when combined with expiratory flow limitation (EFL) lead to worsening dynamic mechanics and earlier exercise cessation [27, 30, 31]. Additionally, the associated tachypnea and shallow breathing during exercise further increase dead space to tidal volume ratio $\left(V_{\mathrm{D}} / V_{\mathrm{T}}\right)[28]$.

Critical arterial hypoxemia $(<60 \mathrm{mmHg})$ due to the presence of lung units with low ventilation-perfusion ratios combined with low 

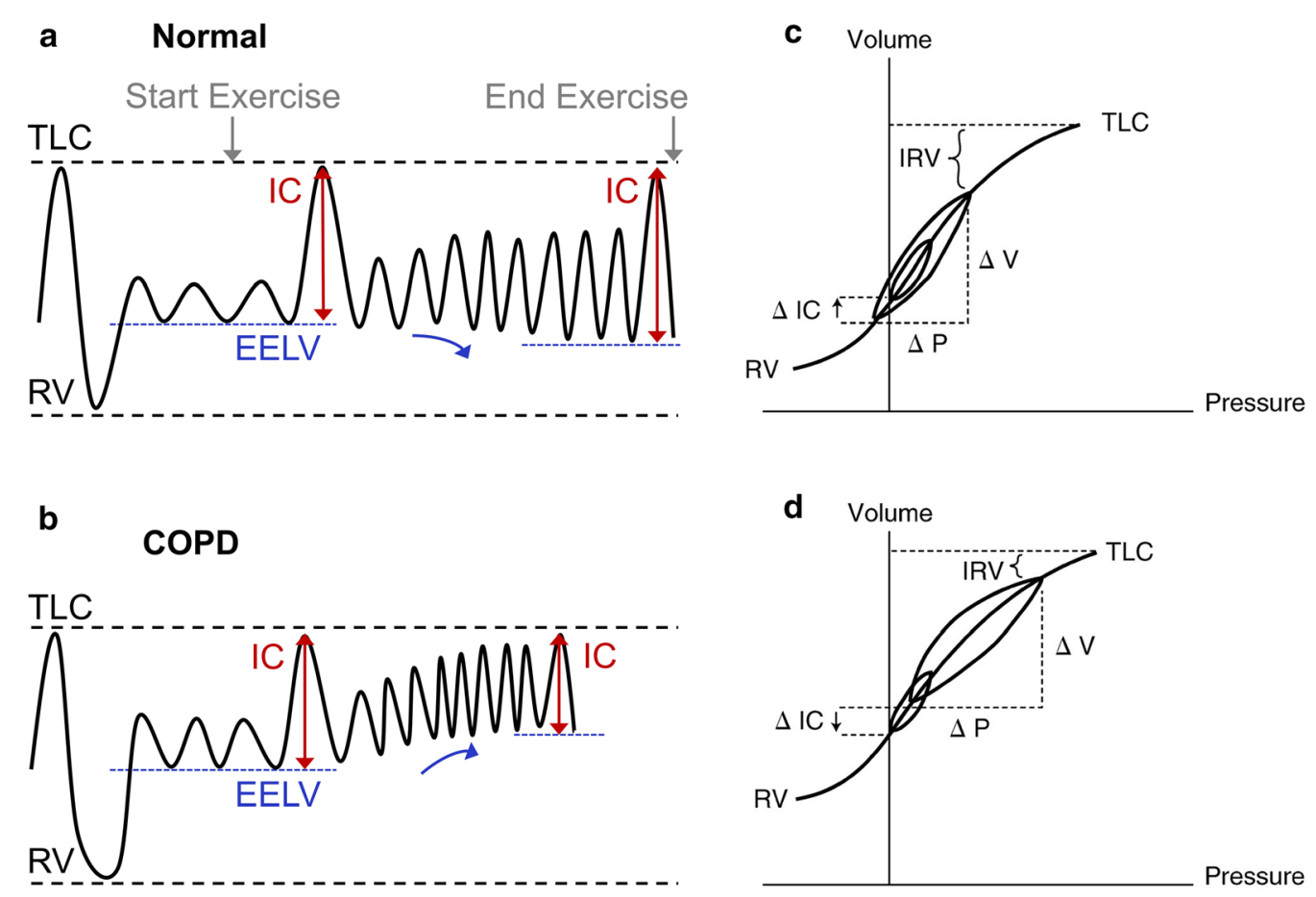

Fig. 3 Change in EELV, IC, and IRV during exercise in a normal lungs and $\mathbf{b}$ COPD demonstrating change in position of $V_{\mathrm{T}}$ relative to TLC on pressure-volume curve $(\mathbf{c}, \mathbf{d})$ of the respiratory system. COPD chronic obstructive pulmonary disease, $E E L V$ end-expiratory lung volume, $I C$ inspiratory capacity, $I R V$ inspiratory reserve volume, $R V$ residual volume, $T L C$ total lung capacity, $V_{T}$ tidal volume.

mixed venous $\mathrm{O}_{2}$ will stimulate peripheral and central chemoreceptors and further increase IND [32-35]. The rate of rise of IND during exercise is also strongly influenced by augmented chemosensitivity as manifested by a lower partial pressure of arterial $\mathrm{CO}_{2}\left(\mathrm{PaCO}_{2}\right)$ at rest. The respiratory control centers adjust to maintain $\mathrm{PaCO}_{2}$ within a narrow range during rest and exercise: the lower the resting $\mathrm{PaCO}_{2}$ level, the higher the IND, $V_{\mathrm{A}}$, and $V_{\mathrm{E}}$ during exercise $[35,36]$. The co-existence of increased chemosensitivity and high physiological dead space greatly augments IND and associated dyspnea.

In COPD, skeletal muscle deconditioning (reduced oxidative capacity) manifests as metabolic acidosis at relatively low $\mathrm{VO}_{2}$ (low anaerobic threshold)—an additional powerful ventilatory stimulus [37-41]. Exercise
Reprinted with permission of the American Thoracic Society. Copyright (c) 2019 American Thoracic Society. O'Donnell DE. 2006. Hyperinflation, dyspnea, and exercise intolerance in chronic obstructive pulmonary disease. Proc Am Thorac Soc. 3(2):180-184. The Annals of the American Thoracic Society is an official journal of the American Thoracic Society

hyperpnea is also provoked by ascending sensory inputs from thinly myelinated (type III and IV) afferents in the active locomotor muscles [34] responding to mechanical distortion and metabolite accumulation during exercise [42].

\section{Dynamic Respiratory Mechanics}

While expiratory flow limitation (EFL) is the hallmark of COPD, associated lung hyperinflation has important negative sensory consequences [43]. Emphysematous destruction of the lungs' connective tissue matrix leads to increased lung compliance and this resets the balance of forces between inward lung recoil pressure and outward chest wall recoil at endexpiration. As a result, the relaxation volume of the respiratory system (i.e., end-expiratory lung volume, EELV) is increased compared with healthy controls (Fig. 3). In patients with EFL, 
EELV is also dynamically determined and is a continuous variable that is influenced by the prevailing breathing pattern. If breathing frequency (Bf) increases abruptly (and expiratory time decreases and/or $V_{\mathrm{T}}$ increases) in patients with significant EFL, air trapping is inevitable, given the slow mechanical time-constant for lung emptying in COPD. Thus, during exercise, EELV increases temporarily and variably above its resting value: this is termed dynamic lung hyperinflation [44-50].

The resting IC and inspiratory reserve volume (IRV) indicate the operating position of $V_{\mathrm{T}}$ relative to total lung capacity (TLC) and the upper curvilinear portion of the relaxed respiratory system S-shaped pressure-volume relationship (Fig. 3). Breathing close to TLC means that the inspiratory muscles are foreshortened, functionally weakened, and must contend with increased elastic and inspiratory threshold loading (to overcome auto-positive end-expiratory pressure, PEEP). The difference between end-inspiratory lung volume (EILV) and TLC (i.e., the size of the IRV) largely dictates the relationship between IND and the mechani$\mathrm{cal} /$ muscular response of the respiratory system and hence the degree of dyspnea experienced throughout exercise. In other words, the dynamic decrease in IRV provides crucial information about the extent of neuromechanical dissociation of the respiratory system and correlates strongly with dyspnea intensity ratings. The smaller the resting IC and IRV (the greater the increase in resting EELV), the shorter the time during exercise before $V_{\mathrm{T}}$ reaches an inflection or plateau and dyspnea abruptly escalates. Thus, when the $V_{\mathrm{T}} / \mathrm{IC}$ ratio reaches approximately 0.7 during exercise, a widening disparity occurs between IND and the $V_{\mathrm{T}}$ response [51]. IND continues to rise and $V_{\mathrm{T}}$ expansion becomes progressively constrained and eventually fixed, representing the onset of severe neuromechanical dissociation [43]. At this point the qualitative descriptor "increased breathing effort" is displaced by "unsatisfied inspiration" as the dominant descriptor of dyspnea [52].

Dynamic hyperinflation results in a relatively rapid and shallow breathing pattern: the attendant increased velocity of shortening of the inspiratory muscles results in functional muscle weakness, decreases dynamic lung compliance, worsening pulmonary gas exchange (higher $V_{\mathrm{D}} / V_{\mathrm{T}}$ ) and negative cardiopulmonary interactions (reduced venous return and reduced left ventricular ejection fraction) [53-56]. With increasing mechanical impairment and progressive resting lung hyperinflation as COPD progresses, these abnormal physiological events appear at progressively lower exercise intensities.

\section{IMPROVING INSPIRATORY NEURAL DRIVE}

\section{Can We Reduce Inspiratory Neural Drive?}

Unfortunately, high physiological dead space is virtually immutable in COPD especially when the cause is emphysematous destruction of the pulmonary vascular bed. First-line dyspnea-relieving therapies such as bronchodilators, which reduce regional lung hyperinflation and improve breathing pattern, result in only small increases in $V_{\mathrm{A}}$ and $V_{\mathrm{E}}$ with essentially no change in dead space ventilation, at least in mild to moderate COPD [57]. In more advanced COPD, modest increases in pulmonary blood flow can occur following bronchodilators and endoscopic lung volume reduction [58, 59]. Inhaled or oral vasodilator therapy also has the potential to improve pulmonary blood flow in selected patients with COPD [60]. However, the overall sensory benefits of improving regional pulmonary blood flow will depend on the net effect on ventilation-perfusion matching and in particular the degree of attenuation of wasted ventilation and reduction of IND. A summary of the interventions for dyspnea management reviewed below is presented in Table 3 .

\section{Supplemental Oxygen}

Hyperoxia inhibits carotid chemoreceptor stimulation of $V_{\mathrm{E}}$ during exercise by reducing $\mathrm{Bf}$, resulting in a reduction in $V_{\mathrm{E}}$ by approximately 3-6 L/min (Fig. 4) [61]. Additionally, improved $\mathrm{O}_{2}$ delivery to the active locomotor 
Table 3 Summary of therapeutic interventions, respective mechanisms, and examples of previously studied therapies for dyspnea alleviation in COPD

\begin{tabular}{|c|c|c|c|}
\hline Goal & Therapy & Mechanism & Example of use \\
\hline \multirow[t]{2}{*}{ Reduce IND } & $\mathrm{O}_{2}^{\mathrm{a}}$ & $\begin{array}{l}\text { Inhibition of carotid chemoreceptor } \\
\text { stimulation } \\
\text { Delay lactate accumulation } \\
\downarrow D H \text { (achieved by } \downarrow \mathrm{Bf} \text { ) }\end{array}$ & $\begin{array}{l}\text { Selection of oxygen delivery system, device, } \\
\text { and flow rate must be tailored to the patient } \\
\text { to best support mobility and quality of life } \\
\text { [107]. Delivery system options include: } \\
\text { Liquid oxygen } \\
\text { Stationary or portable oxygen concentrator } \\
\text { Compressed gas cylinders } \\
\text { Device options include: } \\
\text { Nasal cannula } \\
\text { Simple mask } \\
\text { Reservoir nasal cannula }\end{array}$ \\
\hline & Opiates & $\begin{array}{l}\text { Alteration of central processing of } \\
\text { dyspnea-stimulating afferent signals }\end{array}$ & $\begin{array}{l}\text { Initial dose and titration of opioids must be } \\
\text { personalized with monitoring for adverse } \\
\text { effects. Previously studied opioids in } \\
\text { COPD: } \\
\text { Orally administered morphine (both } \\
\text { immediate release and sustained release) dose } \\
\text { range } 5 \mathrm{mg} \text { to } 40 \mathrm{mg} \text { [72] }\end{array}$ \\
\hline \multirow[t]{2}{*}{$\begin{array}{l}\text { Improve } \\
\text { respiratory } \\
\text { mechanics }\end{array}$} & Bronchodilators & $\begin{array}{l}\downarrow \text { DH (improve airway conductance and } \\
\quad \downarrow \text { time constant, } \uparrow \text { IC and delay critical } \\
\quad \downarrow \text { IRV) } \\
\downarrow \text { Mechanical loading ( } \downarrow \text { elastic and } \\
\text { inspiratory threshold loads) and } \\
\uparrow \text { functional inspiratory muscle strength }\end{array}$ & $\begin{array}{l}\text { Previously studied LABA/LAMA } \\
\text { combinations }[90,92]: \\
\text { Tiotropium-olodaterol 5-5 } \mu \text { g inhaled daily } \\
\text { Umeclidinium bromide-vilanterol } \\
62.5-25 \mu \mathrm{g} \text { inhaled daily }\end{array}$ \\
\hline & $\mathrm{IMT}^{\mathrm{b}}$ & $\begin{array}{l}\uparrow \text { Functional inspiratory muscle strength } \\
\text { at given } V_{\mathrm{E}} \text { and operating lung } \\
\text { volumes }\end{array}$ & $\begin{array}{l}\text { Previously studied IMT [96]: } \\
30 \text { breaths ( } 4-5 \text { min sessions) twice to three } \\
\text { times daily using handheld POWERbreathe } \\
\text { KH2 device for } 8 \text { weeks }\end{array}$ \\
\hline
\end{tabular}


Table 3 continued

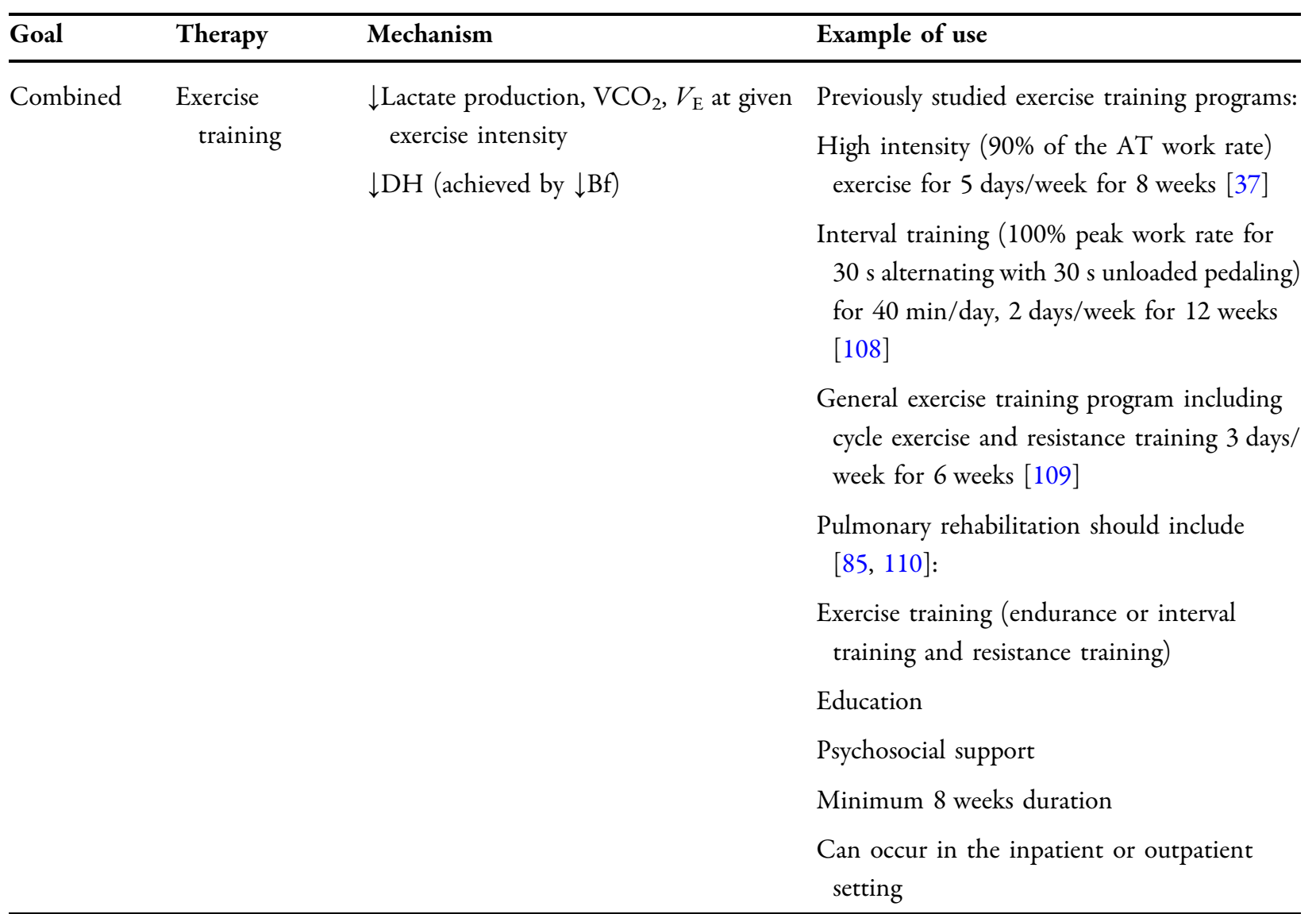

$A T$ anaerobic threshold, $B f$ breathing frequency, $C O P D$ chronic obstructive pulmonary disease, $D H$ dynamic hyperinflation, $I C$ inspiratory capacity, IMT inspiratory muscle training, IND inspiratory neural drive, $I R V$ inspiratory reserve volume, $L A B A$ long-acting beta-2 agonist, $L A M A$ long-acting muscarinic antagonist, PImax maximum inspiratory pressure

a Survival benefit demonstrated in subjects with resting $\mathrm{PaO} 2 \leq 55 \mathrm{mmHg}$ or $\mathrm{PaO} 2<60 \mathrm{mmHg}$ with cor pulmonale, right heart failure, or erythrocytosis $[64,65]$. Qualification for long-term domiciliary oxygen varies by jurisdiction

b In patients with COPD and inspiratory muscle weakness defined as PImax $<70 \mathrm{cmH}_{2} \mathrm{O}$ [96]

muscles delays lactate accumulation (hydrogen ion stimulation), and likely alters afferent inputs from peripheral muscle ergoreceptors. The effects of $\mathrm{O}_{2}$ on IND and $V_{\mathrm{E}}$ are more pronounced in patients with significant baseline arterial hypoxemia but some individuals with milder exercise arterial $\mathrm{O}_{2}$ desaturation can also benefit [33, 61-63]. Other established benefits of supplemental $\mathrm{O}_{2}$ include reduced dynamic hyperinflation secondary to reduced $\mathrm{Bf}$, improved cardiocirculatory function (e.g., reduced pulmonary artery resistance), and delayed skeletal muscle fatigue [34]. The relative contribution of these altered physiological responses to dyspnea relief during exercise will vary across individuals.

Landmark clinical trials assessing the use of oxygen therapy in COPD have demonstrated the mortality benefit of continuous ambulatory oxygen in patients with significant hypoxemia $[64,65]$. A recent systematic review examined 44 studies that assessed the impact of supplemental ambulatory oxygen on symptoms in patients with COPD who did not qualify for supplemental oxygen on the basis of thresholds from landmark studies (mean $\mathrm{PaO}_{2}>55 \mathrm{mmHg}$ ). Oxygen supplementation reduced dyspnea in patients undergoing 

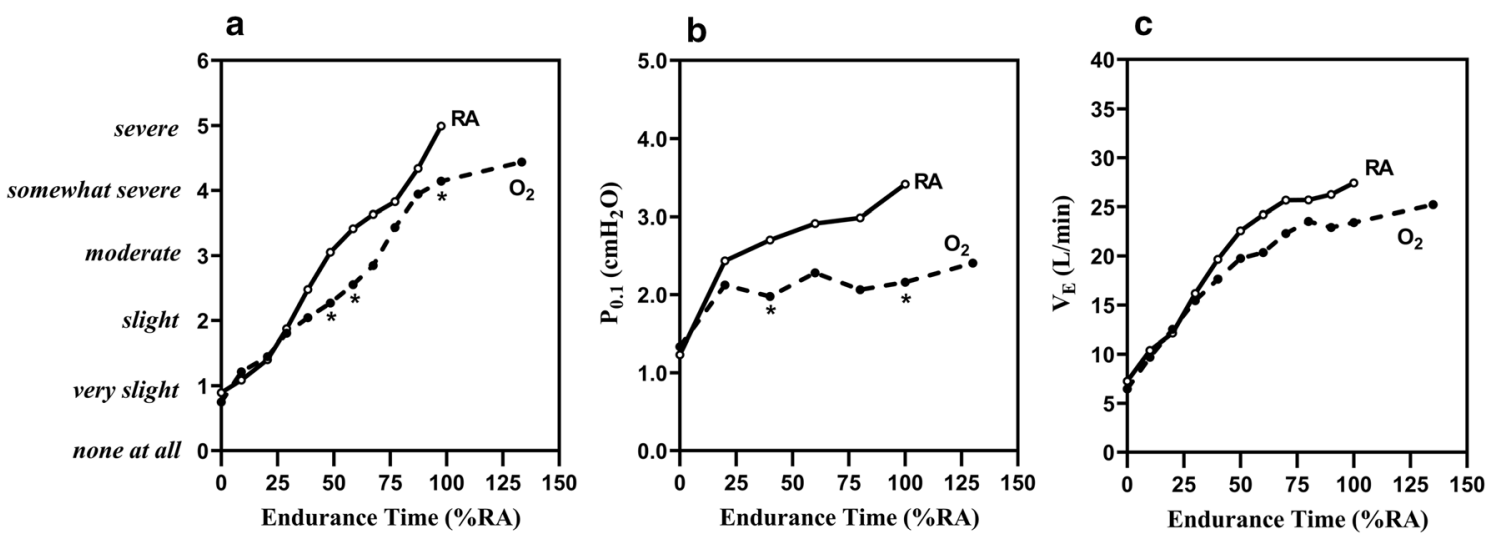

Fig. 4 Improvement in a dyspnea, b $P_{0.1}$ (a surrogate measure of inspiratory neural drive), and c $V_{\mathrm{E}}$ with administration of oxygen in patients with moderate to severe COPD and mild exertional oxygen desaturation, not qualifying for ambulatory home oxygen. $R A$ room air, $P_{0.1}$ airway occlusion pressure, $V_{E}$ minute ventilation. Reprinted with permission of the American Thoracic Society.

cardiopulmonary exercise testing compared to patients exercising without oxygen; however, evidence of an effect on daily activities was limited [63-65].

\section{Opiates}

Respiratory depression is a well-recognized complication of opioid therapy in susceptible older patients with more advanced COPD [66-72]. In clinically stable patients with COPD, careful upward titration of opiate medication is generally safe in selected patients. Abdallah et al. [73] have recently shown that a single dose of fast-acting, orally administered morphine in patients with COPD was associated with improvements in dyspnea and exercise endurance but with considerable variation in response [73]. Of interest, this subjective improvement occurred in the absence of significant decreases in IND (EMGdi/EMGdi,max), $\mathrm{Bf}$, and $V_{\mathrm{E}}$. The authors speculated that opiates may alter the central processing of sensory signaling related to dyspnea and may influence the affective dimension by acting on abundant opioid receptors in cortico-limbic centers of the brain.

Although opioids are recommended for dyspnea management in patients with chronic
Copyright (C) 2019 American Thoracic Society. O’Donnell DE, Bain DJ, Webb KA. 1997. Factors contributing to relief of exertional breathlessness during hyperoxia in chronic airflow limitation. Am J Respir Crit Care Med. 155(2):530-535. The American Journal of Respiratory and Critical Care Medicine is an official journal of the American Thoracic Society

lung disease [1], a recent systematic review of 26 studies that investigated the role of various opiates for palliation of refractory breathlessness in advanced disease determined that opiates provided a minor improvement in breathlessness scores compared to placebo ( -3.36 from baseline on $100 \mathrm{~mm}$ visual analog scale [VAS]; minimal clinically important difference [MCID] - 9) [74]. These studies, which included patients with refractory breathlessness despite optimal medical management, provided weak evidence for oral and parenteral administration of opiates, and no evidence for nebulized administration [74]. A recently published randomized controlled trial (RCT) evaluating the impact of regular sustained-release orally administered morphine for chronic breathlessness (modified Medical Research Council $[\mathrm{mMRC}] \geq 2$ ) in patients with a range of diagnoses, including COPD, found no difference in dyspnea severity reduction between orally administered morphine and placebo arms of the study [75]. However, subjects in the morphine arm used less as needed rescue immediate release orally administered morphine [75]. 


\section{Exercise Training}

In one important study, a high intensity exercise training (EXT) program was associated with consistent physiological training effects such as reduced lactic acid, $\mathrm{VCO}_{2}$, and $V_{\mathrm{E}}$ at a given exercise intensity (Fig. 5) [37]. Such improvements in acid-base status likely reduce IND and dyspnea by altering central and peripheral chemoreceptor activation, in part reflecting altered activation patterns of locomotor muscle ergoreceptors. The associated reduced Bf has been shown to reduce dynamic hyperinflation with consequent delay of intolerable dyspnea [76-79]. However, it is now clear that important improvements in activity-related dyspnea, quality of life, and perceived self-efficacy can occur in the absence of consistent physiological training effects in patients with more advanced COPD [80]. Thus, supervised multicomponent, pulmonary rehabilitation programs appear to positively modify behavior and address the important affective component of dyspnea [81]. This is corroborated by a recent study which demonstrated that pulmonary rehabilitation in COPD consistently altered brain activity in

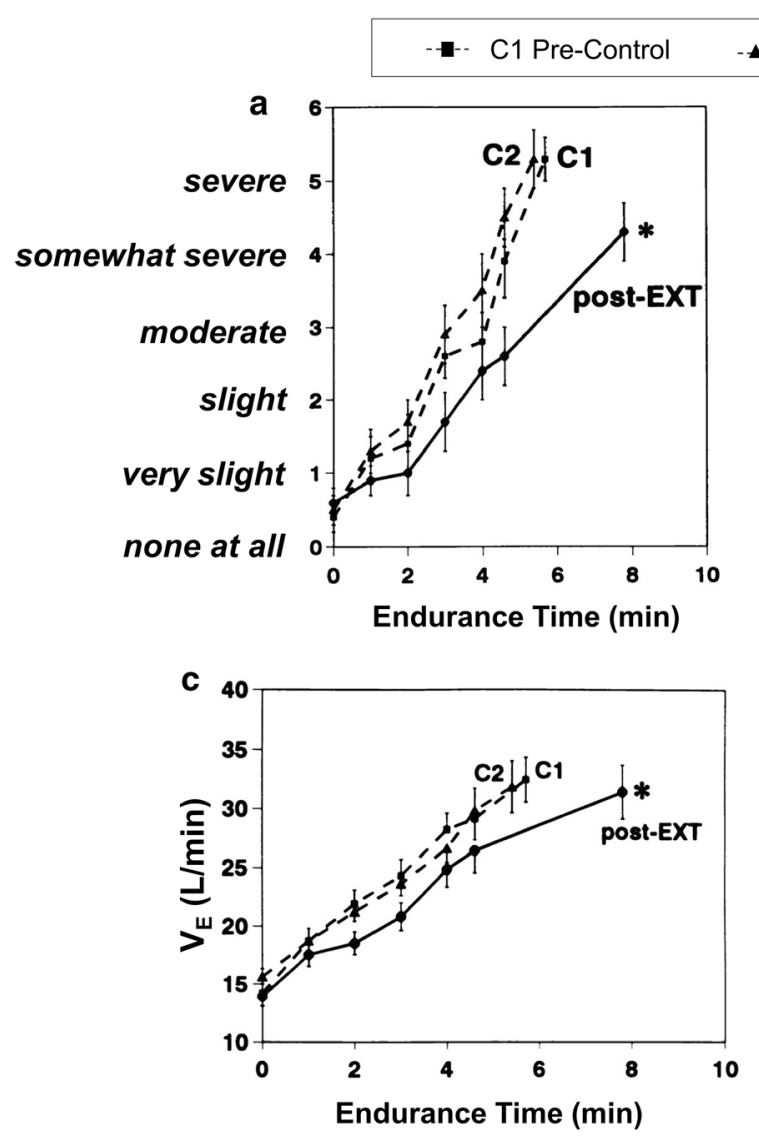

-- C2 Post-Control $\rightarrow$ Post EXT
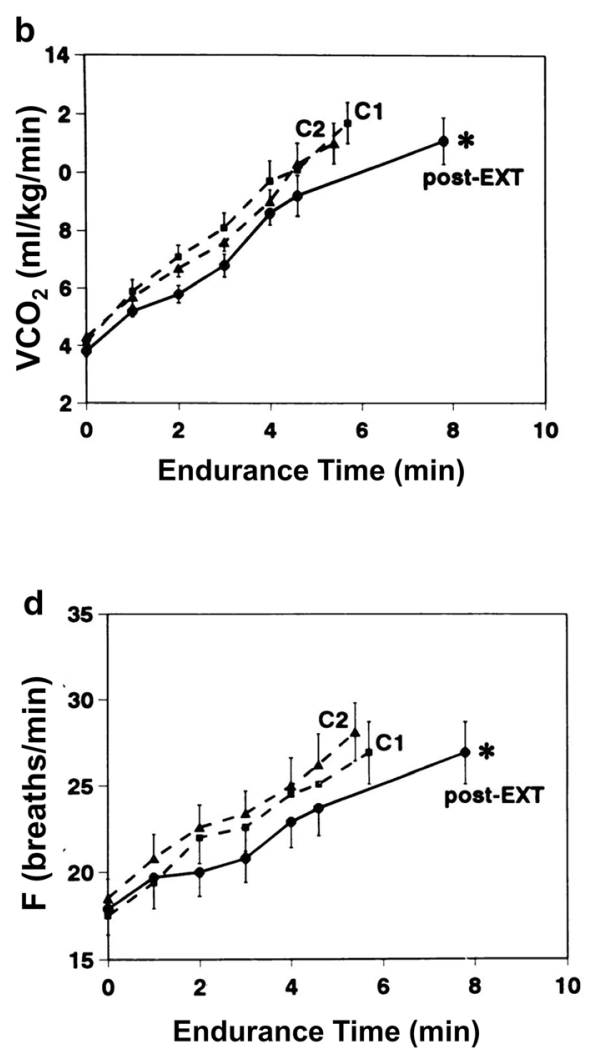

Fig. 5 Reduced a exertional breathlessness during constant-load cycle exercise after exercise training (EXT) or control intervention in patients with COPD. Slopes of b carbon dioxide output $\left(\mathrm{VCO}_{2}\right)$, c ventilation $\left(V_{\mathrm{E}}\right)$, and d breathing frequency also fell significantly after EXT. ${ }^{*} p<0.05$. COPD chronic obstructive pulmonary disease, EXT exercise training, $F$ breathing frequency, $\mathrm{VCO}_{2}$ carbon dioxide production, $V_{E}$ minute ventilation, $V_{T}$ tidal volume. Reprinted with permission of the American
Thoracic Society. Copyright (C) 2019 American Thoracic Society. O’Donnell DE, McGuire M, Samis L, Webb KA. 1998. General exercise training improves ventilatory and peripheral muscle strength and endurance in chronic airflow limitation. Am J Respir Crit Care Med. 157(5):1489-1497. The American Journal of Respiratory and Critical Care Medicine is an official journal of the American Thoracic Society 
stimulus valuation networks, measured by brain fMRI [82]. A systematic review of 65 RCTs of pulmonary rehabilitation programs demonstrated significant improvement in dyspnea and pulmonary rehabilitation is recommended in international guidelines for patients with COPD and persistent dyspnea [83-85]. It was noted that these programs enhanced the patients' sense of control over their condition and significantly improved health-related quality of life [83].

\section{IMPROVING VENTILATORY CAPACITY: RESPIRATORY MECHANICS AND MUSCLE FUNCTION}

\section{Reducing Lung Hyperinflation}

Bronchodilators improve airway conductance and shorten the time constant for lung emptying. In this way, they reduce lung hyperinflation [86]. The resultant increase in IC and IRV allows greater $V_{\mathrm{T}}$ expansion and higher $V_{\mathrm{E}}$ during exercise with a delay in reaching critical mechanical limits where dyspnea becomes intolerable [30]. Increased IC at rest and during exercise means that $V_{\mathrm{T}}$ occupies a lower position on the sigmoidal pressure-volume curve of the relaxed respiratory system (Fig. 6). Thus, the net effect is reduced intrinsic mechanical loading (i.e., elastic and inspiratory threshold loads) and increased functional strength of the inspiratory muscles. Ultimately, lung deflation partially restores a more harmonious relationship between IND and $V_{\mathrm{T}}$ displacement: less effort is now required for a given or greater $V_{\mathrm{T}}$ (Fig. 6) [87-89].

The superiority of dual combined long-acting beta-2 agonist and muscarinic antagonist (LABA/LAMA) bronchodilators relative to the individual mono-components is modest at best [90, 91]. A systematic review of 99 RCTs indicates that while dual long-acting bronchodilators often reduce dyspnea, increase lung function (improved forced expiratory volume in $\left.1 \mathrm{~s}, \mathrm{FEV}_{1}\right)$, and improve quality of life compared to single long-acting bronchodilators or LABA/ inhaled corticosteroid (ICS) combinations [92], these results are not consistent and vary in magnitude. Current guidelines recommend LABA/LAMA combination therapy for patients whose symptoms are not controlled by a single long-acting bronchodilator [84, 93-95].

\section{Inspiratory Muscle Training (IMT)}

In a recent study Langer et al. [96] showed that supervised IMT in patients with severe COPD and baseline inspiratory muscle weakness was associated with increased inspiratory muscle
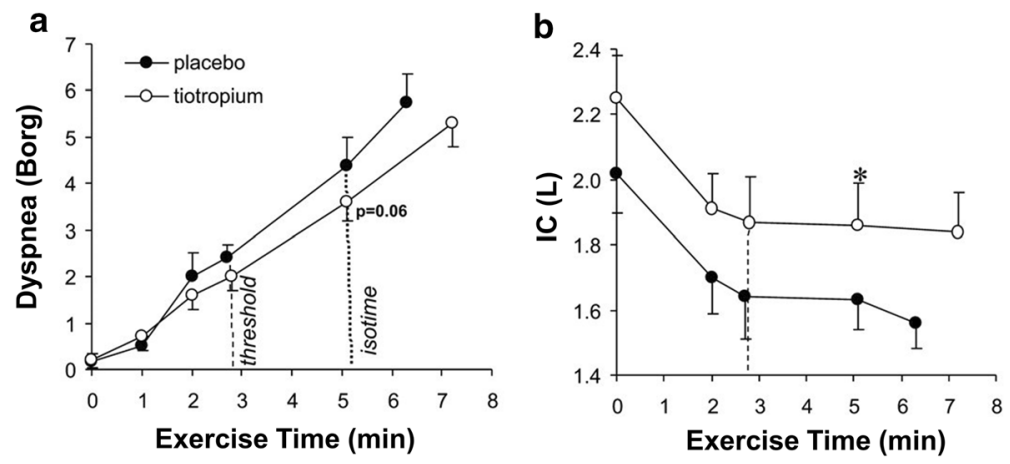

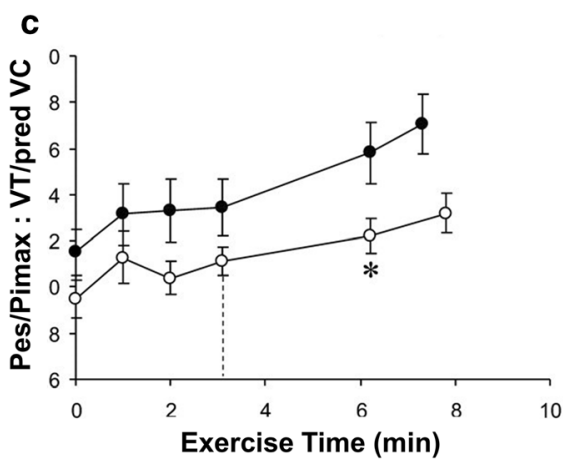

Fig. 6 Ventilatory responses to CWR exercise between tiotropium and placebo demonstrating reduced $\mathbf{b}$ dynamic hyperinflation with c improved musculo-mechanical coupling and a reduced dyspnea. $C W R$ constant work rate, $I C$ inspiratory capacity, Pes/PImax tidal esophageal pressure relative the maximum esophageal inspiratory pressure, $V_{T}$ tidal volume. Adapted from O’Donnell DE, Hamilton AL, Webb KA. Sensory-mechanical relationships during highintensity, constant-work-rate exercise in COPD. J Appl Physiol. 2006;101(4):1025-1035 


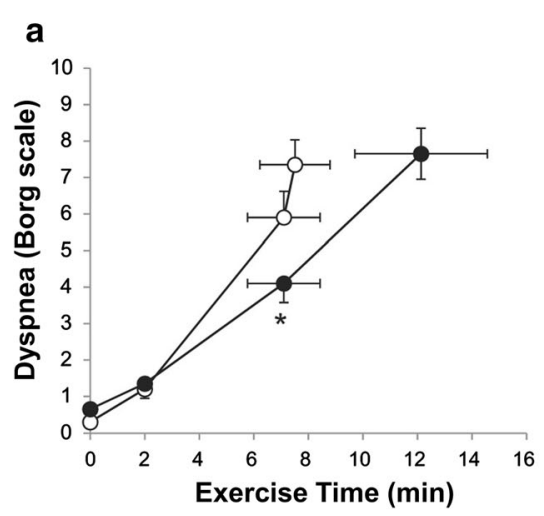

Fig. 7 Improvement in $\mathbf{a}$ dyspnea, $\mathbf{b}$ inspiratory neural drive (EMGdi/EMGdi,max), and c ventilation following IMT in patients with COPD and evidence of inspiratory muscle weakness. COPD chronic obstructive pulmonary disease, $E M G d i / E M G d i$, max index of inspiratory neural drive to the crural diaphragm, IMT inspiratory muscle

strength, reduced dyspnea, and improved exercise tolerance compared with sham training (Fig. 7). In the active IMT group, IND fell significantly over the increased exercise endurance time ( $>3 \mathrm{~min}$ ) during which $V_{\mathrm{E}}$ was sustained at approximately $30 \mathrm{~L} / \mathrm{min}$ (Fig. 7). Of interest, IND (EMGdi/EMGdi,max) was diminished after IMT in a setting of no change in $V_{\mathrm{E}}$, breathing pattern, or operating lung volumes. This study, therefore, supports the notion that when the inspiratory muscles are weakened in COPD, the rise in IND during exercise reflects increasing motor command output from cortical centers in the brain to maintain force generation commensurate with the ventilatory demand. The increased IND under these conditions contributed to exertional dyspnea: reduced IND and dyspnea as muscle function improved supports this contention.

A meta-analysis of 32 RCTs on the effects of IMT in patients with COPD spanning all disease severities showed that IMT led to a significant reduction in dyspnea (Borg score - 0.9 units; TDI +2.8 units) compared to patients without IMT [97]. A systematic review of studies that evaluated the utility of IMT in patients with COPD showed that IMT reduces symptoms of dyspnea (Borg scale - 0.52 units difference, IMT vs. control; baseline and transition dyspnea training, $V_{E}$ minute ventilation. Adapted from Langer $\mathrm{D}$, Ciavaglia C, Faisal A, Webb KA, Neder JA, Gosselink R, Dacha S, Topalovic M, Ivanova A, O'Donnell DE. Inspiratory muscle training reduces diaphragm activation and dyspnea during exercise in COPD. J Appl Physiol. 2018;125(2):381-392

index [BDI-TDI]: 2.30 units difference, IMT vs. control). The minimal clinically important difference for TDI is 1 unit [98]. There was no benefit of adjunctive IMT in patients completing a pulmonary rehabilitation program [99].

\section{CHALLENGES OF DYSPNEA MANAGEMENT IN COPD}

Effective dyspnea management for patients with COPD presents an important challenge requiring comprehensive clinical history taking and a basic understanding of the neurophysiological mechanisms of dyspnea as discussed. Multiple contributory factors often exist and need to be identified and treated to optimize individual management. These include negative effects of obesity or malnutrition, anxiety and depression, and impairment in cardiocirculatory and musculoskeletal function. The symptom of dyspnea is a uniquely personal experience and difficult to quantify numerically with magnitude-of-tasks questionnaires (mMRC) or even multicomponent questionnaires which evaluate intensity, quality, affective dimension, and impact on quality of life (BDI-TDI) [98, 100, 101]. 


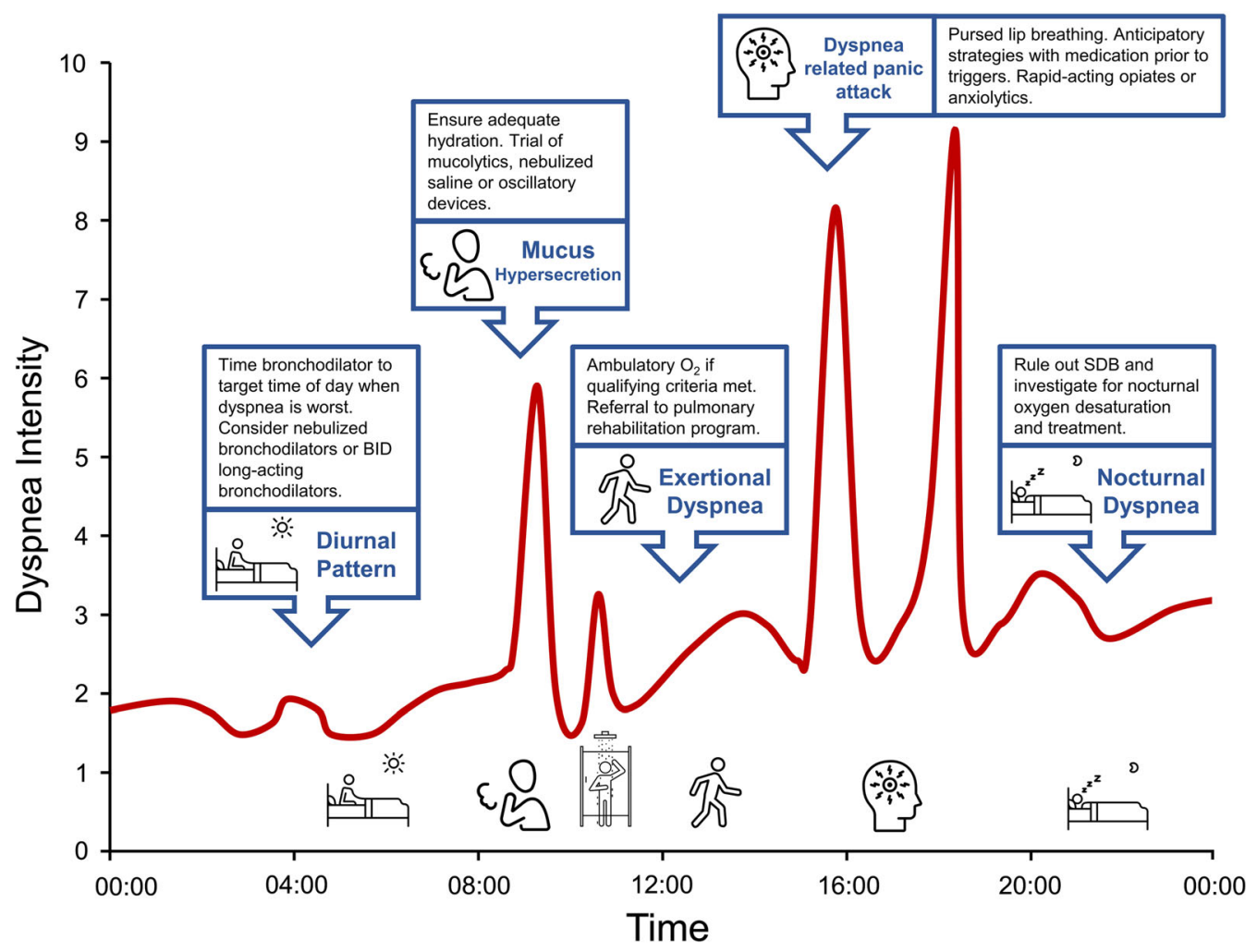

Fig. 8 Individual dyspnea intensity profile of a patient with COPD and highlighted management interventions targeting dyspnea triggers and underlying physiological

Patients with COPD may present with very different individual dyspnea profiles (Fig. 8). Some patients experience increased nighttime and early morning dyspnea. Distressing dyspnea is often provoked by bouts of coughing and difficult sputum expectoration. Dyspnea may be predominantly associated with physical activity or be characterized by a gradual increase in intensity and fatigue throughout the day, punctuated by episodes of "breakthrough" dyspnea or crisis. Each scenario requires a personalized approach to management that ideally is tailored to the individual's dyspnea profile.

According to most current recommendations [1], the first step in alleviating dyspnea in COPD is to optimize bronchodilator therapy to improve respiratory mechanics and muscle function, thus increasing exercise capacity. The second step is to promote regular physical activity or, if at all possible, to enroll the patient in a supervised, multidisciplinary pulmonary mechanisms. $B I D$ twice daily, $C O P D$ chronic obstructive pulmonary disease, $S D B$ sleep disordered breathing. Icons presented in the figure from the Noun Project

rehabilitation program. A recent study has demonstrated that patients with moderate to severe chronic activity-related breathlessness are not referred to pulmonary rehabilitation programs despite evidence that these patients derive benefit [102]. Potential additional benefits of pulmonary rehabilitation include improved peripheral muscle function and acid-base balance with reduced IND and secondary improvements in dynamic respiratory mechanics and muscle function. Individualized inspiratory muscle training may benefit some patients with advanced COPD who have objective inspiratory muscle weakness. For selected individuals with severe dyspnea and significant arterial $\mathrm{O}_{2}$ desaturation during $\left(\mathrm{SpO}_{2}<88 \% \mathrm{O}_{2}\right.$ for more than two consecutive minutes) a weight-bearing endurance test, a trial of ambulatory $\mathrm{O}_{2}$ treatment should be considered to facilitate increased physical activity. Opiates are generally reserved for patients with 
incapacitating dyspnea and need to be carefully supervised.

Taken together, the majority of clinical trials on efficacy of common treatment interventions report only minor gains in dyspnea alleviation compared with placebo. This reflects the vast pathophysiological heterogeneity of COPD with consequent variability in response patterns to any single intervention. Many dyspnea assessment instruments, currently at our disposal, lack the sensitivity to measure the longitudinal impact of single or combined interventions on the daily burden of dyspnea. It must be emphasized that multidisciplinary management is generally required for refractory dyspnea and this should be tailored to the specific needs of the individual, determined by careful evaluation. Thus, refinements in evaluation of patterns of precipitation of dyspnea and individual daily profiles might offer greater precision in the future development of more effective symptom management.

\section{ACKNOWLEDGEMENTS}

Funding. No funding or sponsorship was received for this study or publication of this article.

Authorship. All named authors meet the International Committee of Medical Journal Editors (ICMJE) criteria for authorship for this article, take responsibility for the integrity of the work as a whole, and have given their approval for this version to be published.

Disclosures. Dr. DE O'Donnell has received research funding via Queen's University from Canadian Institutes of Health Research, Canadian Respiratory Research Network, AstraZeneca, and Boehringer Ingelheim and has served on speaker bureaus, consultation panels and advisory boards for AstraZeneca, Boehringer Ingelheim, and Novartis. Dr. JA Neder has received research funding via Queen's University from Boehringer Ingelheim and has served on speaker bureaus, consultation panels and advisory boards for AstraZeneca, Chiesi
Farmaceutici, Boehringer Ingelheim, and Novartis. Mr. Matthew D. James, Dr. Kathryn M. Milne, and Dr. Juan Pablo de Torres have nothing to disclose.

Compliance with Ethics Guidelines. This article is based on previously conducted studies and does not contain any studies with human participants or animals performed by any of the authors.

Data Availability. Data sharing is not applicable to this article as no datasets were generated or analyzed during the current study.

Open Access. This article is distributed under the terms of the Creative Commons Attribution-NonCommercial 4.0 International License (http://creativecommons.org/licenses/ by-nc/4.0/), which permits any noncommercial use, distribution, and reproduction in any medium, provided you give appropriate credit to the original author(s) and the source, provide a link to the Creative Commons license, and indicate if changes were made.

\section{REFERENCES}

1. Parshall MB, Schwartzstein RM, Adams L, et al. An official American Thoracic Society statement: update on the mechanisms, assessment, and management of dyspnea. Am J Respir Crit Care Med. 2012;185(4):435-52.

2. Pumar MI, Gray CR, Walsh JR, Yang IA, Rolls TA, Ward DL. Anxiety and depression-important psychological comorbidities of COPD. J Thorac Dis. 2014;6(11):1615-31.

3. Maltais F, Decramer M, Casaburi R, et al. An official American Thoracic Society/European Respiratory Society statement: update on limb muscle dysfunction in chronic obstructive pulmonary disease. Am J Respir Crit Care Med. 2014;189(9):e15-62.

4. Jones NL. The ins and outs of breathing: how we learnt about the body's most vital function. Bloomington: iUniverse; 2011.

5. Jensen D, Ofir D, O'Donnell DE. Effects of pregnancy, obesity and aging on the intensity of perceived breathlessness during exercise in healthy humans. Respir Physiol Neurobiol. 2009;167:87-100. 
6. Killian KJ, Gandevia SC, Summers E, Campbell EJ. Effect of increased lung volume on perception of breathlessness, effort, and tension. J Appl Physiol. 1984;57(3):686-91.

7. El-Manshawi A, Killian KJ, Summers E, Jones NL. Breathlessness during exercise with and without resistive loading. J Appl Physiol. 1986;61(3):896-905.

8. Lane R, Adams L, Guz A. Is low-level respiratory resistive loading during exercise perceived as breathlessness? Clin Sci. 1987;73:627-34.

9. Campbell EJ, Gandevia SC, Killian KJ, Mahutte CK, Rigg JR. Changes in the perception of inspiratory resistive loads during partial curarization. J Physiol. 1980;309:93-100.

10. Moosavi SH, Topulos GP, Hafter A, et al. Acute partial paralysis alters perceptions of air hunger, work and effort at constant $\mathrm{P}(\mathrm{CO}(2))$ and $\mathrm{V}(\mathrm{E})$. Respir Physiol. 2000;122:45-60.

11. Banzett RB, Lansing RW, Brown R, et al. 'Air hunger' from increased $\mathrm{PCO} 2$ persists after complete neuromuscular block in humans. Respir Physiol. 1990;81(1):1-17.

12. O'Donnell DE, Hong HH, Webb KA. Respiratory sensation during chest wall restriction and dead space loading in exercising men. J Appl Physiol. 2000;88(5):1859-69.

13. Chen Z, Eldridge FL, Wagner PG. Respiratory-associated thalamic activity is related to level of respiratory drive. Respir Physiol. 1992;90(1):99-113.

14. Chen Z, Eldridge FL, Wagner PG. Respiratory-associated rhythmic firing of midbrain neurones in cats: relation to level of respiratory drive. J Physiol. 1991;437:305-25.

15. Eldridge FL, Millhorn DE, Waldrop TG. Exercise hyperpnea and locomotion: parallel activation from the hypothalamus. Science. 1981;211(4484):844-6.

16. Gandevia SC, Killian K, McKenzie DK, et al. Respiratory sensations, cardiovascular control, kinaesthesia and transcranial stimulation during paralysis in humans. J Physiol. 1993;470:85-107.

17. von Leupoldt A, Sommer T, Kegat S, et al. The unpleasantness of perceived dyspnea is processed in the anterior insula and amygdala. Am J Respir Crit Care Med. 2008;177(9):1026-32.

18. Stoeckel MC, Esser RW, Gamer M, Buchel C, von Leupoldt A. Brain responses during the anticipation of dyspnea. Neural Plast. 2016;2016:6434987.
19. Jolley CJ, Luo YM, Steier J, Rafferty GF, Polkey MI, Moxham J. Neural respiratory drive and breathlessness in COPD. Eur Respir J. 2015;45(2):355-64.

20. Jolley CJ, Luo YM, Steier J, et al. Neural respiratory drive in healthy subjects and in COPD. Eur Respir J. 2009;33(2):289-97.

21. Lou YM, Hart N, Mustfa N, Lyall RA, Polkey MI, Moxham J. Effect of diaphragm fatigue on neural respiratory drive. J Appl Physiol. 2001;90(5):1691-9.

22. Lou YM, Lyall RA, Harris ML, et al. Effect of lung volume on the oesophageal diaphragm EMG assessed by magnetic phrenic nerve stimulation. Eur Respir J. 2000;15(6):1033-8.

23. Lou YM, Moxham J. Measurment of neural respiratory drive in patients with COPD. Respir Physiol Neurobiol. 2005;146(2-3):165-74.

24. Faisal A, Alghamdi BJ, Ciavaglia CE, et al. Common mechanisms of dyspnea in chronic interstitial and obstructive lung disorders. Am J Respir Crit Care Med. 2016;193(3):299-309.

25. Guenette JA, Chin RC, Cheng S, et al. Mechanisms of exercise intolerance in Global Initiative for Chronic Obstructive Lung Disease grade 1 COPD. Eur Respir J. 2014;44(5):1177-87.

26. Elbehairy AF, Guenette JA, Faisal A, et al. Mechanisms of exertional dyspnoea in symptomatic smokers without COPD. Eur Respir J. 2016;48(3):694-705.

27. Elbehairy AF, Ciavaglia CE, Webb KA, et al. Pulmonary gas exchange abnormalities in mild chronic obstructive pulmonary disease: implications for dyspnea and exercise intolerance. Am J Respir Crit Care Med. 2015;191(12):1384-94.

28. Neder JA, Berton DC, Muller PT, et al. Ventilatory inefficiency and exertional dyspnea in early chronic obstructive pulmonary disease. Ann Am Thorac Soc. 2017;14(Supplement_1):S22-9.

29. Hueper K, Vogel-Claussen J, Parikh MA, et al. Pulmonary microvascular blood flow in mild chronic obstructive pulmonary disease and emphysema: the MESA COPD study. Am J Respir Crit Care Med. 2015;192(5):570-80.

30. Chin RC, Guenette JA, Cheng S, et al. Does the respiratory system limit exercise in mild chronic obstructive pulmonary disease? Am J Respir Crit Care Med. 2013;187(12):1315-23.

31. Ofir D, Laveneziana P, Webb KA, Lam YM, O'Donnell DE. Mechanisms of dyspnea during cycle exercise in symptomatic patients with GOLD stage I 
chronic obstructive pulmonary disease. Am J Respir Crit Care Med. 2008;177(6):622-9.

32. Amann M, Regan MS, Kobitary M, et al. Impact of pulmonary system limitations on locomotor muscle fatigue in patients with COPD. Am J Physiol Regul Integr Comp Physiol. 2010;299(1):314-24.

33. O'Donnell DE, D'Arsigny C, Webb KA. Effects of hyperoxia on ventilatory limitation during exercise in advanced chronic obstructive pulmonary disease. Am J Respir Crit Care Med. 2001;163(4):892-8.

34. Ponikowski PP, Chua TP, Francis DP, Capucci A, Coats AJ, Piepoli MF. Muscle ergoreceptor overactivity reflects deterioration in clinical status and cardiorespiratory reflex control in chronic heart failure. Circulation. 2001;104(19):2324-30.

35. Porszasz J, Emtner M, Goto S, Somfay A, Whipp BJ, Casaburi R. Exercise training decreases ventilatory requirements and exercise-induced hyperinflation at submaximal intensities in patients with COPD. Chest. 2005;128(4):2025-34.

36. Ward SA, Whipp BJ. Kinetics of the ventilatory and metabolic responses to moderate-intensity exercise in humans following prior exercise-induced metabolic acidaemia. New Front Respir Control. 2009;669:323-6.

37. Casaburi R, Patessio A, Ioli F, Zanaboni S, Donner $\mathrm{CF}$, Wasserman K. Reductions in exercise lactic acidosis and ventilation as a result of exercise training in patients with obstructive lung disease. Am Rev Respir Dis. 1991;143(1):9-18.

38. Patessio A, Casaburi R, Carone M, Appendini L, Donner CF, Wasserman K. Comparison of gas exchange, lactate, and lactic acidosis thresholds in patients with chronic obstructive pulmonary disease. Am RevRespir Dis. 1993;148(3):622-6.

39. Maltais F, Leblanc P, Simard C, et al. Skeletal muscle adaptation to endurance training in patients with chronic obstructive pulmonary disease. Am J Respir Crit Care Med. 1996;154(2):442-7.

40. Maltais F, Simard AA, Simard C, Jobin J, Desgagnés $P$, Leblanc P. Oxidative capacity of the skeletal muscle and lactic acid kinetics during exercise in normal subjects and in patients with COPD. Am J Respir Crit Care Med. 1996;153(1):288-93.

41. Sue DY, Chung MM, Grosvenor M, Wasserman K. Effect of altering the proportion of dietary fat and carbohydrate on exercise gas exchange in normal subjects. Am Rev Respir Dis. 1989;139(6):1430-4.

42. Gagnon P, Bussieres JS, Ribeiro F, et al. Influences of spinal anesthesia on exercise tolerance in patients with chronic obstructive pulmonary disease. Am J Respir Crit Care Med. 2012;186(7):606-15.

43. O'Donnell DE. Hyperinflation, dyspnea, and exercise intolerance in chronic obstructive pulmonary disease. Proc Am Thorac Soc. 2006;3(2):180-4.

44. Olafsson S, Hyatt RE. Ventilatory mechanics and expiratory flow limitation during exercise in normal subjects. J Clin Invest. 1969;48(3):564-73.

45. Dodd DS, Brancatisano T, Engel LA. Chest wall mechanics during exercise in patients with severe chronic air-flow obstruction. Am Rev Respir Dis. 1984;129(1):33-8.

46. Stubbing DG, Pengelly LD, Morse JLC, Jones NL. Pulmonary mechanics during exercise in subjects with chronic airflow obstruction. J Appl Physiol. 1980;49:511-5.

47. Similowski T, Yan S, Gauthier AP, Macklem PT, Bellemare F. Contractile properties of the human diaphragm during chronic hyperinflation. N Engl J Med. 1991;325(13):917-23.

48. O'Donnell DE, Travers J, Webb KA, et al. Reliability of ventilatory parameters during cycle ergometry in multicentre trials in COPD. Eur Respir J. 2009;34(4):866-74.

49. Puente-Maestu L, Palange P, Casaburi R, et al. Use of exercise testing in the evaluation of interventional efficacy: an official ERS statement. Eur Respir J. 2016;47(2):429-60.

50. Palange P, Ward SA, Carlsen KH, et al. Recommendations on the use of exercise testing in clinical practice. Eur Respir J. 2007;29(1):185-209.

51. O'Donnell DE, Guenette JA, Maltais F, Webb KA. Decline of resting inspiratory capacity in COPD: the impact on breathing pattern, dyspnea, and ventilatory capacity during exercise. Chest. 2012;141(3):753-62.

52. Laveneziana P, Webb KA, Ora J, Wadell K, O'Donnell DE. Evolution of dyspnea during exercise in chronic obstructive pulmonary disease: impact of critical volume constraints. Am J Respir Crit Care Med. 2011;184(12):1367-73.

53. Laveneziana $P$, Palange $P$, Ora J, Martolini D, O'Donnell DE. Bronchodilator effect on ventilatory, pulmonary gas exchange, and heart rate kinetics during high-intensity exercise in COPD. Eur J Appl Physiol. 2009;107(6):633-43.

54. Laveneziana P, Valli G, Onorati P, Paoletti P, Ferrazza AM, Palange P. Effect of heliox on heart rate kinetics and dynamic hyperinflation during high- 
intensity exercise in COPD. Eur J Appl Physiol. 2011;111(2):225-34.

55. Chiappa GR, Borghi-Silva A, Ferreira LF, et al. Kinetics of muscle deoxygenation are accelerated at the onset of heavy-intensity exercise in patients with COPD: relationship to central cardiovascular dynamics. J Appl Physiol. 2008;104(5):1341-50.

56. Berton DC, Barbosa PB, Takara LS, et al. Bronchodilators accelerate the dynamics of muscle $\mathrm{O} 2$ delivery and utlisation during exercise in COPD. Thorax. 2010;65(7):588-93.

57. Elbehairy AF, Webb KA, Laveneziana P, Domnik NJ, Neder JA, O'Donnell DE. Acute bronchodilator therapy does not reduce wasted ventilation during exercise in COPD. Respir Physiol Neurobiol. 2018;252-253:64-71.

58. Vogel-Claussen J, Schönfeld C-O, Kaireit TF, et al. Effect of indacaterol/glycopyrronium on pulmonary perfusion and ventilation in hyperinflated COPD patients (CLAIM): a double-blind, randomised, crossover trial. Am J Respir Crit Care Med. 2019;199:1086-96.

59. Estepar RS, Kinney GL, Black-Shinn JL, et al. Computed tomographic measures of pulmonary vascular morphology in smokers and their clinical implications. Am J Respir Crit Care Med. 2013;188(2):231-9.

60. Iyer KS, Newell J, Jin D, et al. Quantitative dualenergy computed tomography supports a vascular etiology of smoking-induced inflammatory lung disease. Am J Respir Crit Care Med. 2016;193(6):652-61.

61. Peters MM, Webb KA, O'Donnell DE. Combined physiological effects of bronchodilators and hyperoxia on exertional dyspnoea in normoxic COPD. Thorax. 2006;61(7):559-67.

62. O'Donnell DE, Bain DJ, Webb KA. Factors contributing to relief of exertional breathlessness during hyperoxia in chronic airflow limitation. Am J Respir Crit Care Med. 1997;155(2):530-5.

63. Ekström M, Ahmadi Z, Bornefalk-Hermansson A, Abernethy A, Currow D. Oxygen for breathlessness in patients with chronic obstructive pulmonary disease who do not qualify for home oxygen therapy. Cochrane Database Syst Rev 2016;(11):CD006429.

64. Nocturnal Oxygen Therapy Trial Group. Continuous or nocturnal oxygen therapy in hypoxemic chronic obstructive lung disease: a clinical trial. Ann Intern Med. 1980;93(3):391-8.
65. Stuart-Harris C, Bishop JM, Clark TJH, et al. Long term domiciliary oxygen therapy in chronic hypoxic cor pulmonale complicating chronic bronchitis and emphysema: report of the Medical Research Council working party. Lancet. 1981;317(8222):681-6.

66. Vozoris NT, Wang X, Austin PC, et al. Adverse cardiac events associated with incident opioid drug use among older adults with COPD. Eur J Clin Pharmacol. 2017;73(10):1287-95.

67. Vozoris NT, Wang X, Fischer HD, et al. Incident opioid drug use and adverse respiratory outcomes among older adults with COPD. Eur Respir J. 2016;48(3):683-93.

68. Vozoris NT, Wang X, Fischer HD, et al. Incident opioid drug use among older adults with chronic obstructive pulmonary disease: a population-based cohort study. Br J Clin Pharmacol. 2016;81(1):161-70.

69. Jensen D, Alsuhail A, Viola R, Dudgeon DJ, Webb KA, O'Donnell DE. Inhaled fentanyl citrate improves exercise endurance during high-intensity constant work rate cycle exercise in chronic obstructive pulmonary disease. J Pain Symptom Manag. 2012;43(4):706-19.

70. Johnson MJ, Bland JM, Oxberry SG, Abernethy AP, Currow DC. Opioids for chronic refractory breathlessness: patient predictors of beneficial response. Eur Respir J. 2013;42(3):758-66.

71. Rocker GM, Simpson AC, Horton R, et al. Opioid therapy for refractory dyspnea in patients with advanced chronic obstructive pulmonary disease: patients' experiences and outcomes. CMAJ Open. 2013;1(1):E27-36.

72. Ekstrom M, Nilsson F, Abernethy AA, Currow DC. Effects of opioids on breathlessness and exercise capacity in chronic obstructive pulmonary disease: a systematic review. Ann Am Thorac Soc. 2015;12(7):1079-92.

73. Abdallah SJ, Wilkinson-Maitland C, Saad N, et al. Effect of morphine on breathlessness and exercise endurance in advanced COPD: a randomised crossover study. Eur Respir J. 2017;50(4):1701235.

74. Barnes H, McDonald J, Smallwood N, Manser R. Opioids for the palliation of refractory breathlessness in adults with advanced disease and terminal illness. Cochrane Database Syst Rev. 2016;3(3):CD011008.

75. Currow D, Louw S, McCloud P, et al. Regular, sustained-release morphine for chronic breathlessness: a multicentre, double-blind, randomised, placebo- 
controlled trial. Thorax. 2019. https://doi.org/10. 1136/thoraxjnl-2019-213681.

76. O'Donnell DE, Webb KA. Exertional breathlessness in patients with chronic airflow limitation: the role of lung hyperinflation. Am Rev Respir Dis. 1993;148(5):1351-7.

77. Somfay A, Porszasz J, Lee SM, Casaburi R. Dose-response effect of oxygen on hyperinflation and exercise endurance in nonhypoxaemic COPD patients. Eur Respir J. 2001;18(1):77-84.

78. O’Donnell DE, D'Arsigny C, Fitzpatrick M, Webb KA. Exercise hypercapnia in advanced chronic obstructive pulmonary disease: the role of lung hyperinflation. Am J Respir Crit Care Med. 2002;166(5):663-8.

79. Laveneziana $\mathrm{P}$, Webb KA, Wadell K, Neder JA, O'Donnell DE. Does expiratory muscle activity influence dynamic hyperinflation and exertional dyspnea in COPD? Respir Physiol Neurobiol. 2014;199:24-33.

80. Wadell K, Webb KA, Preston ME, et al. Impact of pulmonary rehabilitation on the major dimensions of dyspnea in COPD. COPD. 2013;10(4):425-35.

81. Gordon CS, Waller JW, Cook RM, Cavalera SL, Lim WT, Osadnik CR. Effect of pulmonary rehabilitation on symptoms of anxiety and depression in COPD: a systematic review and meta-analysis. Chest. 2019;156(1):80-91.

82. Herigstad M, Faull OK, Hayen A, et al. Treating breathlessness via the brain: changes in brain activity over a course of pulmonary rehabilitation. Eur Respir J. 2017;50(3):1701029.

83. McCarthy B, Casey D, Devane D, Murphy K, Murphy E, Lacasse Y. Pulmonary rehabilitation for chronic obstructive pulmonary disease. Cochrane Database Syst Rev. 2015;2:CD003793.

84. Global Initiative for Chronic Obstructive Lung Disease. Global strategy for the diagnosis, management, and prevention of chronic obstructive pulmonary disease (2019 report). 2019. https:// goldcopd.org/. Accessed 5 Sept 2019.

85. Spruit MA, Singh SJ, Garvey C, et al. An official American Thoracic Society/European Respiratory Society statement: key concepts and advances in pulmonary rehabilitation. Am J Respir Crit Care Med. 2013;188(8):e13-64.

86. O'Donnell DE, Laveneziana P. The clinical importance of dynamic lung hyperinflation in COPD. COPD. 2006;3:219-32.
87. O'Donnell DE, Hamilton AL, Webb KA. Sensorymechanical relationships during high-intensity, constant-work-rate exercise in COPD. J Appl Physiol. 2006;101(4):1025-35.

88. O'Donnell DE, Sciurba F, Celli B, et al. Effect of fluticasone propionate/salmeterol on lung hyperinflation and exercise endurance in COPD. Chest. 2006;130(3):647-56.

89. O'Donnell DE, Voduc N, Fitzpatrick M, Webb KA. Effect of salmeterol on the ventilatory response to exercise in chronic obstructive pulmonary disease. Eur Respir J. 2004;24(1):86-94.

90. Calzetta L, Ora J, Cavalli F, Rogliani P, O’Donnell DE, Cazzola M. Impact of LABA/LAMA combination on exercise endurance and lung hyperinflation in COPD: a pair-wise and network meta-analysis. Respir Med. 2017;129:189-98.

91. Calzetta L, Rogliani P, Matera MG, Cazzola M. A systematic review with meta-analysis of dual bronchodilation with LAMA/LABA for the treatment of stable COPD. Chest. 2016;149(5):1181-96.

92. Oba Y, Keeney E, Ghatehorde N, Dias S. Dual combination therapy versus long-acting bronchodilators alone for chronic obstructive pulmonary disease (COPD): a systematic review and network meta-analysis. Cochrane Database Syst Rev 2018;(12):CD012620.

93. O'Donnell DE, Aaron S, Bourbeau J, et al. Canadian Thoracic Society recommendations for management of chronic obstructive pulmonary disease2007 update. Can Respir J. 2007;14:5B-32B.

94. Wedzicha JA, Calverley PMA, Albert RK, et al. Prevention of COPD exacerbations: a European Respiratory Society/American Thoracic Society guideline. Eur Respir J. 2017;50(3):1602265.

95. Qaseem A, Wilt TJ, Weinberger SE, et al. Diagnosis and management of stable chronic obstructive pulmonary disease: a clinical practice guideline update from the American College of Physicians, American College of Chest Physicians, American Thoracic Society, and European Respiratory Society. Ann Intern Med. 2011;155(3):179-91.

96. Langer D, Ciavaglia CE, Faisal A, et al. Inspiratory muscle training reduces diaphragm activation and dyspnea during exercise in COPD. J Appl Physiol. 2018;125:381-92.

97. Gosselink R, De Vos J, van den Heuvel SP, Segers J, Decramer M, Kwakkel G. Impact of inspiratory muscle training in patients with COPD: what is the evidence? Eur Respir J. 2011;37(2):416-25. 
98. Mahler DA, Waterman LA, Ward J, McCusker C, ZuWallack R, Baird JC. Validity and responsiveness of the self-administered computerized versions of the baseline and transition dyspnea indexes. Chest. 2007;132(4):1283-90.

99. Beaumont M, Forget P, Couturaud F, Reychler G. Effects of inspiratory muscle training in COPD patients: a systematic review and meta-analysis. Clin Respir J. 2018;12(7):2178-88.

100. Banzett RB, O'Donnell CR, Guilfoyle TE, et al. Multidimensional dyspnea profile: an instrument for clinical and laboratory research. Eur Respir J. 2015;45(6):1681-91.

101. Banzett RB, Moosavi SH. Measuring dyspnoea: new multidimensional instruments to match our 21st century understanding. Eur Respir J. 2017;49(3):1602473.

102. Kochovska S, Fazekas B, Hensley M, Wheatley J, Allcroft P, Currow DC. A randomized, double-blind, multisite, pilot, placebo-controlled trial of regular, low-dose morphine on outcomes of pulmonary rehabilitation in COPD. J Pain Symptom Manag. 2019. https://doi.org/10.1016/j.jpainsymman.2019. 07.026 .

103. Means JH. Dyspnea: medical monograph, vol. 5. Baltimore: Williams \& Wilkins; 1924.

104. Cournand A, Richards DW. Pulmonary insufficiency, Part IL discussion of a physiological classification and presentation of clinical tests. Am Rev Tuberc. 1941;44:26-41.

105. Bradley TD, Chartrand DA, Fitting JW, Killian KJ, Grassino A. The relation of inspiratory effort sensation to fatiguing patterns of the diaphragm. Am Rev Respir Dis. 1986;134(6):1119-24.

106. O'Donnell DE, Revill SM, Webb KA. Dynamic hyperinflation and exercise intolerance in chronic obstructive pulmonary disease. Am J Respir Crit Care Med. 2001;164(5):770-7.

107. Jacobs SS, Lederer DJ, Garvey CM, et al. Optimizing home oxygen therapy: an official American Thoracic Society workshop report. Ann Am Thorac Soc. 2018;15(12):1369-81.

108. Vogiatzis I, Nanas S, Roussos C. Interval training as an alternative modality to continuous exercise in patients with COPD. Eur Respir J. 2002;20(1):12-9.

109. O'Donnell DE, McGuire M, Samis L, Webb KA. General exercise training improves ventilatory and peripheral muscle strength and endurance in chronic airflow limitation. Am J Respir Crit Care Med. 1998;157(5 Pt 1):1489-97.

110. Rochester CL, Vogiatzis I, Holland AE, et al. An official American Thoracic Society/European Respiratory Society policy statement: enhancing implementation, use, and delivery of pulmonary rehabilitation. Am J Respir Crit Care Med. 2015;192(11):1373-86. 